\title{
Can Gender Moderate the Relationship of Mindfulness, Procrastination and Job Performance Among Telecom Employees?
}

\author{
Zafar Ahmad $^{\text {a }}$, Malik Mureed Hussain ${ }^{\text {b }}$ \\ ${ }^{a}$ International Islamic University, Islamabad, Pakistan \\ ${ }^{\mathrm{b}}$ Multan Post Graduate College, Multan, Pakistan
}

\begin{tabular}{l}
\hline ARTICLE DETAILS \\
\hline History: \\
Accepted 16 august 2020 \\
Available Online 30 September \\
2020 \\
Keywords: \\
Mindfulness, Procrastination, Job \\
Performance, Job Demand \\
Resource (JDR), gender
\end{tabular}

JEL Classification: J28, j29

\begin{abstract}
Job demand resource model and self-determination theory is widely used for understanding procrastination, mindfulness, job performance and gender in organizational settings. The job demand resource model has been further used to understand gender as moderator among employee's with mindfulness, procrastination and job performance. The present study focuses on gender as moderator in mindfulness, procrastination and job performance among male and female employees. The Purposive sampling technique with cross-sectional approach was applied. Mindfulness Attention Awareness Scale (MAAS; Brown \& Ryan, 2003), Tuckman's Procrastination Scale (TPS; Tuckman, 1991), and Job Performance Scale (JP-S; Wright, Kacmar, Mcmahan, \&Deleeuw, 1995) were used to collect data from 400 employees working in telecom organizations in Rawalpindi and Islamabad city. The t-test and Hayes process were used to study correlation and moderation among study variables. It has been found female employees have mindfulness and procrastination tendencies then male employees whereas male employees were higher on job performance then female employees. Additionally, gender has non-significant effect on mindfulness, procrastination and job performance among employees. The results support the job resource demand model and self-determination theory. According to JDR model, job demands, and resources play important role in job performance of an employee in organizations and selfdetermination theory supports that mindfulness inhibit procrastination behavior and improve job performance of employees in organizations. These findings also suggest that procrastination could inhibit job performance among employees. Therefore, job performance could be stimulated by individual mindfulness in male and female employees.
\end{abstract}

DOI: $10.47067 /$ reads.v6i3.246

(C) 2020 The authors. Published by SPCRD Global Publishing. This is an open access article under the Creative Commons Attribution-

NonCommercial 4.0

Corresponding author's email address:

\section{Introduction}

Job performance has become the core issue globally no matter what sector of employment and organization is the stakeholder. Rapid technological advancements are constantly shadowing the 


\section{Review of Economics and Development Studies, Vol. 6 (3) 2020, 557-566}

manpower and work-force is in debilitating apprehension for this. Despite of organizational and industrial developments, human factor is not completely irreplaceable. However, a larger focus is on enabling and enhancing the performance ratio and cutting the losses in organizations. For this, role of employees is always in limelight. How employees are sustaining interpersonal and intrapersonal stressors, acquiring resources and capacitating to yield outcomes is always a million-dollar question when it comes to reviewing the job performance. Performance is behavior and is closely related to productivity in an organization. Although job performance have several determinants where cognitive or mental ability is one of the determinants of job performance (Schmitt \& Hunter, 2004).

Organizations' face significant loss due to distraction effecting job performances of employees. This poses a question to explore the role of procrastination and how is it counter-dealt by mindfulness. Delaying and alternating the task without any cause, accumulating a burden, deferring work meaninglessly and is a safe regular failure act of doing gratifying things rather less enjoyable ones (Nguyen, Steel, \& Ferrari, 2013). As a result it causes stress and productivity issues at personal level whereas social dissatisfaction on deadlines, responsibilities and commitments. Such failures may combine to create more procrastination. According to Pirson (2014) an incomplete task is one of the most adverse determinants of job performance as its incompletion drains energy and mentally hangs up an individual. Pirson (2014) stated that temporary escape from responsibilities is a hindrance for good job performance whereas conscious alertness for the elimination of delay leads to at least an optimal level of the performance. That conscious alertness is mindfulness, which is cognitive construct, involves a person's mental processing of the multitude of event in the work environment (Dane \& Brummel, 2013).

Mindfulness helps to perform routine task more attentively in efficient and effective manner, regarded as consciously paying attention which indicate attentiveness of mind (Bodhi, 20oo) had constructive effect on the job performance in organization. Dane and Brummel (2014) revealed mindfulness and job performance are positively associated which means that the more mindful the employee were at workplace, more highly their managers rated their job performance. Organizations like Google, Adobe, Roll Royee, General Mill and Genetech are offering mindfulness programs to their employees to improve their job performance.

Procrastination is the intentional choice of a behavior or task on other option. Procrastinator focus on short term pleasure, sensation seeker in the moment instead of concentrating on task completion Steel (2007), lack emotional stability and exhibits high energy levels (Dewitte and Schouwenburg; 2002) and are also aware of significance of task failure, having weak self-control, lack work related discipline, unable to work systematically and face trouble in time management (Dewitte \& Schouwenburg, 2002; Nan Earde, 2003; Milgram \& Tenne, 2000, Steel; 2007)

Gender has its own role on mindfulness and procrastination (Shao \& Skarlicki;2009, Sturgess; 2012,) and found females as more mindful then males whereas male can overcome the emotional experience. Gender have no-significant effect on mindfulness (Short \& Mezo;2010). Males were significantly higher on mindfulness than females because females were face more difficulty to be attentive to positive and negative stimuli as mindfulness demands both stimuli (Slonim, Kienhuis, Di Benedetto, \& Reece; 2015). 


\section{Review of Economics and Development Studies, Vol. 6 (3) 2020, 557-566}

Women were found lower on procrastination which helps them to get more employment then men (Nguyen, Steel \& Ferrari; 2013). Male were found higher on procrastination then female (Ozer, Demir \& Ferrari; 2009) whereas females were also found higher procrastination tendencies (Washington, 2004; Rodarte-Luna \& Sherry; 2008) higher procrastination found in male students (Prohaska, Morrill, Atiles \& Perez, 200o). Significant differences on procrastination where men were higher than women (Balkis \& Duru; 2009) whereas some studies found no relevance of gender on procrastination behaviour (Ozer \& Ferrari; 2011)

\section{Literature Review}

This research is based on theoretical perspective that link procrastination, mindfulness, and job performance at workplace where gender moderates the relationship of these variables. This idea purposed based on job demand resource model, which considers job resources play an important role at workplace and effects employees' performance, wellbeing and procrastination issues. The Job DemandsResources (JD-R) model (Bakker \& Demerouti, 2007; Demerouti et al., 2001) emphasized to predict employee burnout and engagement, and consequently organizational performance. Research has suggested that job resources help to enhance performance at workplace even with high job demands. When an employee gets support from others or has ability to do own work and others help for timely completion of official (Wrzesniewski \& Dutton, 2001) whereas the workplaces with less job resources badly affect employee performance.

However, mindfulness effect job performance and job stress in organizational settings (Teasdale, Segal, \& Williams, 1995; Brown, Ryan, \& Creswell, 2007). According to interacting cognitive subsystem model (Teasdale, Segal \& Williams; 1995) difficult chores create disapproving thoughts and affect consciousness, increase impulsivity and self-criticism whereas mindfulness helps to overcome selfcritical, pessimistic feelings which ultimately lead to task commitment and achievement.

Mindfulness, well-being and performance of employees at workplace are directly linked with each other (Schultz, Ryan, Niemiec, Legate, and Williams; 2015). Workers possessing higher mindfulness don't frustrate in uncooperative environments as it act as defensive factor in such type of organizational work environments. Such findings support mindfulness as a latent way to wellness in organizations, also support autonomy to promote employee well-being and job performance. The conservation of resources theory (COR) was proposed by (Kroon, Menting, and Woerkom; 2015) which focuses on mindfulness, work motivation and performance in an organizational perspective and explained mindfulness in dynamic contexts as believes to provides personal resources to the employees, enable resilience in employees.

Procrastination heavily cost to the companies, as per research it charge about $\$ 10,000$ for a single employee annually (D’Abate \& Eddy, 2007; Steel, 2011). Procrastination and economical gains of at individual levels are negatively associated (Mehrabian, 2000) symptoms of attention deficit hyperactivity disorder (ADHD), showed issues like distraction and disorganization at work (Re Snick, 2005) whereas ADHD reduced earnings by approximately 30\% (Fletcher, 2013).

Procrastination leads to hypertension, cardiovascular diseases and maladaptive coping Sirois (2014). Badly effect mental, physical health and performance in the workplace. People with procrastination tendencies earn less, spend less time in job. It is also found that unemployed people procrastinate more, may lead to unemployment, enhance the likelihood of switching existing position, 
Review of Economics and Development Studies, Vol. 6 (3) 2020, 557-566

job-lock. Enabling individuals to switch job even have slight progress in existing job, connected to poor financial decision making (Value; 2016).

Depending upon available literature the present study conceptualized to understand the gender as moderator between mindfulness, procrastination and job performance of employee in Pakistani culture.

\section{Methodology}

\subsection{Objectives}

1. To study the relationship among mindfulness, procrastination and job performance in telecom sector employees.

2. To investigate the moderating role of gender in relation between mindfulness, procrastination and job performance.

\subsection{Hypotheses}

To following hypotheses were formulated to study mindfulness, procrastination and job performance.

1. Male employees will be higher on procrastination and mindfulness than female employees.

2. The gender will affect the relationship between mindfulness, procrastination and job performance.

\subsection{Sample}

The data was collected from 150 (109 male, 41 females) employees of telecommunication sector of Islamabad and Rawalpindi. The data was collected from all departments of an organization. The data were collected through purposive convenient sampling technique by keeping in view the all ethical consideration. Their participation was totally on voluntarily basis without any pressure or coercion, all the research related information including data collection, analysis and scope were clearly discussed. The use of offensive, discriminatory or unacceptable languages was avoided while giving briefing about questionnaire and data collection. Participants were shared the purpose of study and they were assured about the confidentiality and anonymity of their responses. Since job performance was taken from employees and their managers/officers as well, especially care was taken to keep the process blind to avoid any stigmatization or labeling.

\subsection{Instruments}

The following instruments with demographic sheet were used for measurement.

\subsubsection{Demographic sheet:}

For the purpose of information gathering a demographic sheet was developed mentioning age, gender and other study related demographics.

\subsubsection{Mindfulness Attention Awareness Scale (MAAS):}

The Mindfulness Attention Awareness Scale (Brown \& Ryan, 2003) was a 15-item scale having 6pointLikert such as $(1=$ almost always, 2 =very frequently, $3=$ somewhat frequently, $4=$ somewhat infrequently, 5 = very infrequently, 6 = almost never) used. MAAS has highest 90 and the lowest 15 score which shows higher and lower levels of mindfulness. According to Brown and Ryan (2003) the Cronbach's alpha reliability of this scale was found to be .87 . 


\subsubsection{Tuckman's Procrastination Scale (TPS):}

The scale used to measure procrastination behavior, comprised of 16 items, Likert type scale categories; $(4=$ that's me for sure; 3 = that's my tendency; $2=$ that's not my tendency and $1=$ that's not me for sure). The Cronbach alpha of the scale is .85

\subsubsection{Job Performance Scale (JP-S):}

The scale was used to measure the job performance of the employees (Wright, Kacmar, Mcmahan \& Deleeuw; 1995). The scale has 8 with 5 point Likert scale; strongly disagree (1) to strongly agree (5).

Procedure

For the purpose of data collection, the organizations were contacted. In most of the organizations the human resource department helped in data collection. The complete details regarding research, data collection, confidentiality and usage of the data were shared with the concerned representative of the department. They asked for the questionnaires in first meeting and take some time to review and permission from the head of the department. After clearing their all research related queries, they allowed to collect the data and further guide to the departments and their employees. Now the employees were informed about the research and its scope, they are very keen about the confidentiality of data, they were assured that the data will be kept confidential and will only use for university research purpose. Their names, designations, salary etc will not be shared with anyone else. They were also informed that it's voluntary participation so if anyone wants to leave then they have right to leave. They were explained about Mindfulness Attention Awareness Scale (MAAS), Tuckman Procrastination Scale (TPS) and Job Performance Scale (JP-S). Some of them took 15-20 minutes to fill the questionnaires and return back whereas some employees took few days. The data were collected as per their convenience. Since job performance was taken from employees and their managers/officers as well, especially care was taken to keep the process blind to avoid any stigmatization or labeling.

\section{Results}

Table 1: Mean differences between male and female employees on mindfulness, procrastination and job performance $(\mathrm{N}=400)$

\begin{tabular}{|c|c|c|c|c|c|c|c|c|c|}
\hline \multirow{2}{*}{ Variables } & \multicolumn{2}{|c|}{ Male $(n=305)$} & \multicolumn{2}{|c|}{ Female $(n=95)$} & \multirow{2}{*}{$t(d f)$} & \multirow{2}{*}{$\mathrm{p}$} & \multicolumn{2}{|c|}{$95 \mathrm{Cl} \%$} & \multirow{2}{*}{ Cohen's d } \\
\hline & M & SD & M & SD & & & UL & LL & \\
\hline TPS & 36.82 & 8.54 & 37.60 & $7 \cdot 76$ & -0.78 & 0.43 & -2.71 & 1.16 & 0.09 \\
\hline JP & 56.03 & 8.03 & $55 \cdot 45$ & $7 \cdot 79$ & 0.62 & 0.53 & -1.26 & 2.43 & 0.07 \\
\hline MASS & 58.54 & 13.42 & 60.37 & 11.11 & -1.20 & 0.23 & -4.81 & 1.16 & 0.15 \\
\hline
\end{tabular}

Note. MAAS $=$ Mindfulness Attention Awareness Scale, TPS $=$ Tuckman Procrastination Scale, JP = Job Performance

Table 1 shows non-significant differences among employees on mindfulness, procrastination and job performance where female employees were higher on mindfulness and procrastination then male employees. Although male employees were higher job performance then female employees. 
Review of Economics and Development Studies, Vol. 6 (3) 2020, 557-566

\subsection{Moderation Analysis}

Moderation shows the influence of another variable between the relationships of two variables. Andrew F. Hayes Process Macros Software (Hayes, 2013) was used between two mindfulness and Procrastination and their impact in outcome variable i.e. Job performance in interaction with gender to check about existence of interaction.

Moderation effect of gender between mindfulness and job performance

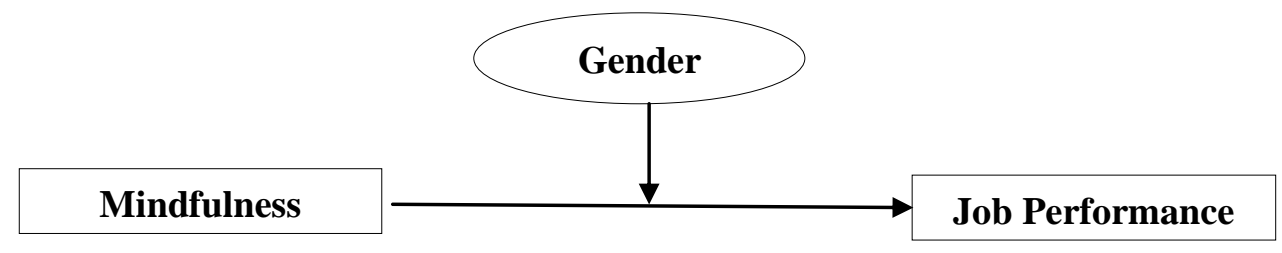

Table 2: Moderation impact of the Gender between Mindfulness and job performance among employees $(\mathrm{N}=400)$

\begin{tabular}{|c|c|c|c|c|c|c|c|c|}
\hline & \multirow[b]{2}{*}{$\mathbf{R}$} & \multirow[b]{2}{*}{$\mathbf{R 2}$} & \multirow{2}{*}{$\begin{array}{l}\text { R2 } \\
\text { Change } \\
/ \Delta R\end{array}$} & \multirow[b]{2}{*}{$\mathbf{F}$} & \multicolumn{2}{|c|}{ Job performance } & \multirow[b]{2}{*}{$\mathbf{T}$} & \multirow[b]{2}{*}{$\mathbf{P}$} \\
\hline & & & & & coefficient & SE & & \\
\hline Model Summary & .5644 & .3185 & & 69.4917 & & & & .0000 \\
\hline Constant & & & & & 32.2499 & 2.3630 & 13.6479 & .0000 \\
\hline Gender & & & & & -.0116 & 3.0892 & -.0037 & .9970 \\
\hline MAAS & & & & & .4249 & .0469 & 9.0567 & .0000 \\
\hline \multirow{2}{*}{\multicolumn{2}{|c|}{$\begin{array}{l}\text { Interaction } \\
\text { MAAS x Gender }\end{array}$}} & & & & .0213 & .0616 & .3466 & .7290 \\
\hline & & & .0002 & .1201 & & & & .7290 \\
\hline
\end{tabular}

Note. MAAS $=$ Mindfulness Attention Awareness Scale

The table 2 shows the moderation results of gender with mindfulness and job performance and found non-significant moderation of gender on mindfulness and job performance of employees.

Moderation effect of gender between procrastination and job performance

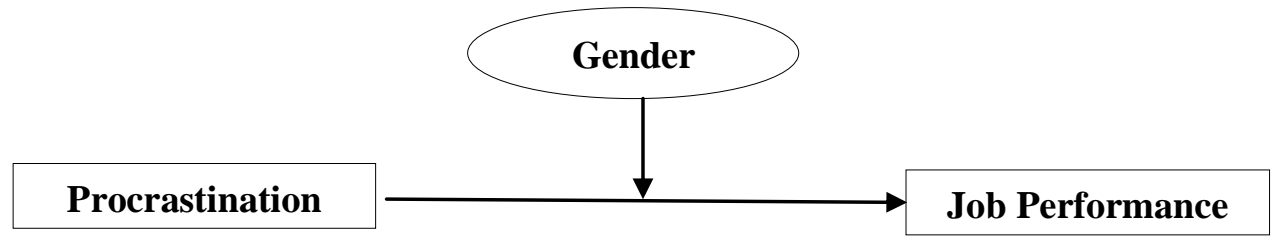

Table 3: Moderation impact of the Gender between Procrastination and job performance among employees $(\mathrm{N}=400)$

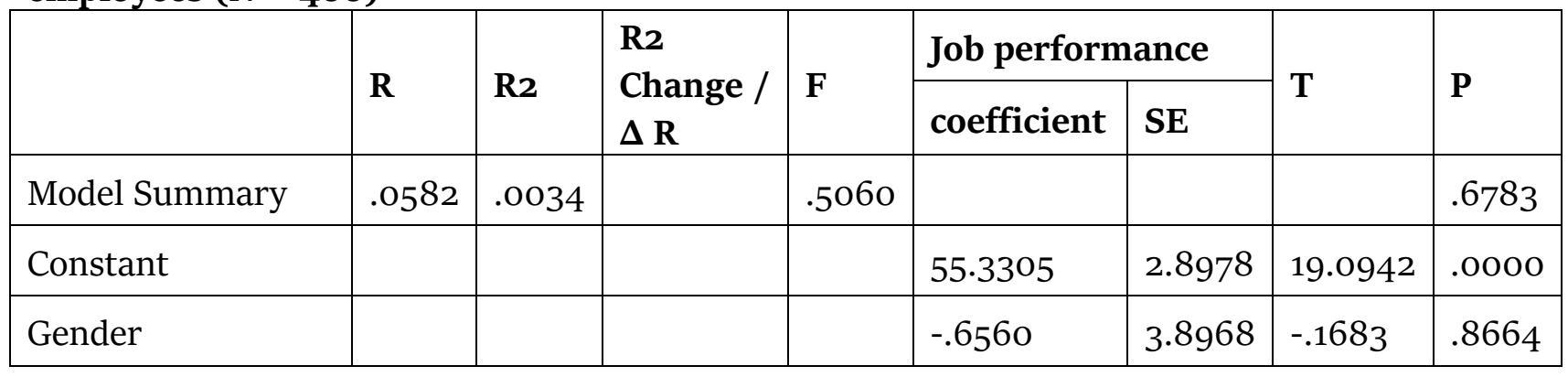


Review of Economics and Development Studies, Vol. 6 (3) 2020, 557-566

\begin{tabular}{|l|l|l|l|l|l|l|l|l|}
\hline TPS & & & & & -.0585 & .0764 & -.7651 & .4446 \\
\hline \multirow{2}{*}{$\begin{array}{c}\text { Interaction } \\
\text { TPS x Gender }\end{array}$} & & & & & .0383 & .1021 & .3747 & .7081 \\
\cline { 2 - 8 } & & & .0003 & .1404 & & & & .7081 \\
\hline
\end{tabular}

Note. TPS = Tuckman Procrastination Scale

The table 3 shows the moderation results of gender with procrastination and job performance and found non-significant moderation of gender on procrastination and job performance of employees.

\section{Discussion}

Job Demand Resource theory/model is widely used concept to understand job demands and job resources whereas Self-determination theory is helpful to understand procrastination, mindfulness and job performance. Previous researches help to understand the relationship of mindfulness and job performance but can't develop consensus (Judge, Thoresen, Bono, \& Patton, 2001). Researches have been conducted with different moderators as rewards, salary, job complexity or self-esteem with diverse findings, some reached on results (Judge et al., 2001; Petty, Mcgee, \& Cavender, 1984) with gender role as moderator in mindfulness, procrastination and job performance. In present study it was proposed that gender effect the relationship of study variables among employees.

Researches on mindfulness contributes that it enable peoples to their surroundings that supports vibrant thought, behavior, stress reduction and decision making, individual draw distinction in routine experiences and become more interested in tasks and performance will improve even if an individual will make small effort to be mindful whereas alternative perspective allows an individual for clearer picture of situation, help to better understanding of things (Langer 2004). Researchers have found mindfulness as psychological state that varies within an individual (Allen \& Kiburz, 2012; Bishop et al., 2004; Brown \& Ryan, 2003; Dane, 2011; Glomb et al., 2011; Heppner et al., 2008; Lau et al., 2006; Robins, Keng, Ekblad, \& Brantley, 2012). Employees confront variety of demands and challenges which affect at emotional and cognitive level (Baumeister, Bratslavsky, Muraven, \& Tice, 1998). Whereas mindfulness enhances self-regulation independently (Brown \& Ryan, 2003), which conserves liveliness and vigor (Ryan \& Deci, 2008). Mindfulness as state explains behavior in specific situation while as attribute is a inclination to reason and act mind fully (Langer, 2004). Mindfulness as state and precisely as trait help to generate substitute perspective with open mindset to improve better decision, overcome cognitive dissonance which causes stress and exhaustion. Circumstantial awareness and societal evaluation related with performance are associated with mindfulness (Langer, Pirson \& Delizonna, 2010), self-acceptance and stress (Carson \& Langer, 2006; Demick, 2000). Mindfulness has suggested task performance at workplace (Dane, 2011; Glomb, Duffy, Bono, \& Yang, 2011) and physiological and psychological health related tasks at work (Glomb et al., 2011).

It was hypothesized that male employees will be more inclined toward procrastination and mindfulness then females employees. To test this differentiation t-test applied to explore gender differences among these variables of study. However, in present study non-significance differentiation was found among gender on procrastination and mindfulness of employees. These findings are in line with the findings of Short and Mezo (2010) reporting non-significant gender differences amongst males and females in their levels of mindfulness. Also, these findings are consistent with the findings of Balkis and Duru (2009) which suggests that procrastination is gender neutral. Similar pattern of nonsignificant findings was also reported by Ozer and Ferrari (2011) who did not found any support for gender difference on procrastination. 


\section{Review of Economics and Development Studies, Vol. 6 (3) 2020, 557-566}

However, findings of present study reported that females score higher on mindfulness and procrastination then male employees whereas male employees score higher on job performance as compare to female's employees (Slonim, Kienhuis, Di Benedetto, \& Reece 2015).

It was hypothesized that gender will affect the relationship of mindfulness, procrastination and job performance. Moderations analysis was performed, with the help of Hayes software macro package (Hayes, 2013) to see the interactive effect of different demographic variables and mindfulness or procrastination on overall job performance of employees. Gender differentiation was found neutral (non-significant) for relationship between mindfulness and job performance $(p=.729)$, for relationship between procrastination and job performance $(\mathrm{p}=.708)$ showing that gender is not moderation effect, to explain any possible interaction with mindfulness or procrastination on job performance. Sabina's (2017) work reflected a strive to review the impact of gender as potential moderator, paving line for present study to re-run similar evidences on this sample. However, for present sample and study is confirming the finding of (Kappen, G; 2019). It is generally believed that women are mindful and give better performance than men (Shao, R., \& Skarlicki, D. P; 2009)

The non-significant differences were found among study variables. Although female were found more on mindfulness and procrastination then male employees whereas male employee were found higher on job performance then female.

\section{Conclusion}

These findings suggest that gender is not inhibiting any role in the relationship of mindfulness, procrastination and job performance in male and female employees. Therefore, on the basis of available data and analysis it has been found that mindfulness, procrastination are not the tendencies which are gender based as no significant differences reported among male and female employees. Although there are differences on job performance.

Limitations could be research design, sample size and self-report measures. In order to conduct further research, it is important to focus on other contextual factors of the organization which are affecting employee mindfulness, developing procrastination behaviors at workplace and results poor job performance at workplace. Future researches should be conducted with personality and different personal attributes.

\section{Implications}

One of the challenges to employees in any workplace setting is related to consistency in job performance despite of all technological advancement. This study is one such effort to establish a correlational dynamic across mindfulness, procrastination and job performance and how variables like gender can play its role. Professional trainings in these both areas are relatively untouched zones and results elaborated that procrastination is a significant factor impact performance negatively thus employees' engagement in mindful activities such as meditative strategies could serve as the effective means. Furthermore, employers can take initiative to instigate mindfulness at workplace to avoid the halting lag of procrastination on work setups.

\section{REFERENCES}

Brown, K. W., Ryan, R. M., \& Creswell, J. D. (2007). Mindfulness: Theoretical foundations and evidence for its salutary effects. Psychological Inquiry, 18(4), 211-237. 


\section{Review of Economics and Development Studies, Vol. 6 (3) 2020, 557-566}

https://doi.org/10.1080/10478400701598298.

Brown, K. W., \& Ryan, R. M. (2003). The benefits of being present: Mindfulness and its role in psychological well-being. Journal of Personality and Social Psychology, 84(4),822-848. https://doi.org/10.1037/0022-3514.84.4.822.

Beheshtifar, M., Hoseinifar, H., \& Moghadam, M. (2011). Effect procrastination on work-related stress. European Journal of Economics, Finance and Administrative Sciences, 38, 59-64.

Chun Chu, A. H., \& Choi, J. N. (2005). Rethinking procrastination: Positive effects of "active" procrastination behavior on attitudes and performance. The Journal of Social Psychology, 145(3), 245-264. https://doi.org/10.3200/SOCP.145.3.245-264.

Cheung, R. Y. M., \& Ng, M. C. Y. (2018). Mindfulness and symptoms of depression and anxiety: The underlying roles of awareness, acceptance, impulse control, and emotion regulation. Mindfulness. https://doi.org/10.1007/s12671-018-1069-y.

Dane, E. \& Brummel, B. J. (2013). Examining workplace mindfulness and its relations to job performance and turnover intention, Human Relations. doi: 10.1177/0018726713487753

Dane, E., \& Brummel, B. J. (2014). Examining workplace mindfulness and its relations to job performance and turnover intention. Human Relations, 67(1):105-128. doi: 10.1177/0018726713487753

Demerouti, E., Bakker, A. B., De Jonge, J., \& Janssen, P. P. (2001). Burnout and engagement at work as a function of demands and Contfol. Scand J Work Environ Health, 27(4).

Ferrari, J. R., O'Callaghan, J., \&Newbegin, I. (2005). Prevalence of procrastination in the United States, United Kingdom, and Australia: Arousal and avoidance delays among adults. North American Journal of Psychology, 7(1), 1-6.

Flett, A. L., Haghbin, M., \&Pychyl, T. A. (2016). Procrastination and depression from a cognitive perspective: An exploration of the associations among procrastinatory automatic thoughts, rumination, and mindfulness. Journal of Rational-Emotive \& Cognitive-Behavior Therapy, 34(3), 169-186. https://doi.org/10.1007/s10942-016-0235-1.

Gustavson, D. E., Miyake, A., Hewitt, J. K., \& Friedman, N. P. (2014). Genetic relations among procrastination, impulsivity, and goal-management ability: Implications for the evolutionary origin of procrastination. Psychological Science, 25(6),1178188.https://doi.org/10.1177/095679761452626o.

Grund, A., \& Fries, S. (2018). Understanding procrastination: A motivational approach. Personality and Individual Differences, 121, 120-130. https://doi.org/10.1016/j.paid. 2017.09.035.

Gagnon, J., Dionne, F., \&Pychyl, T. A. (2016). Committed action: An initial study on its association to procrastination in academic settings. Journal of Contextual Behavioral Science, 5(2), 97-102. https://doi.org/10.1016/j.jcbs.2016.04.002.

Howell, A. J., \&Buro, K. (2011). Relations among mindfulness, achievement-related selfregulation, and achievement emotions. Journal of Happiness Studies, 12(6),1007-1022. https://doi.org/10.1007/s10902-010-9241-7.

Kim, K. R., \&Seo, E. H. (2015). The relationship between procrastination and academic performance: A meta-analysis. Personality and Individual Differences, 82, 26-33. https://doi.org/10.1016/j.paid.2015.02.038.

Kabat-Zinn, J. (1994). Wherever you go, there you are: Mindfulness meditation in everyday life. New York: Hyperion.

Nguyen, B., Steel, P., \& Ferrari, J. R. (2013). Procrastination's impact in the workplace and the workplace's impact on procrastination. International Journal of Selection and Assessment, 21(4), 388-399.

Richardson, M., Abraham, C., \& Bond, R. (2012). Psychological correlates of university students' academic performance: A systematic review and meta-analysis.Psychological Bulletin, 138(2), 
353. https://doi.org/10.1037/aoo26838.

Sirois, F. M., \&Pychyl, T. A. (Eds.). (2016). Procrastination, health, and well-being. Academic Press.

Sirois, F. M., \&Tosti, N. (2012). Lost in the moment? An investigation of procrastination, mindfulness, and well-being. Journal of Rational-Emotive \& Cognitive-Behavior Therapy,30(4), 237-248. https://doi.org/10.1007/s10942-012-0151-y.

Schouwenburg, H. C., Lay, C. H., Pychyl, T. A., \& Ferrari, J. R. (2004). Counselling the procrastinator in academic settings. Washington, DC: American PsychologicalAssociation.

Teasdale, J. D., Segal, Z., \& Williams, J. M. G. (1995). How does cognitive therapy prevent depressive relapse and why should attentional control (mindfulness) training help? Behaviour Research and Therapy, 33(1), 25-39. https://doi.org/10.1016/ooo5-7967(94)Eoo11-7.

Tice, D. M., \&Bratslavsky, E. (2000). Giving in to feel good: The place of emotion regulation in the context of general self-control. Psychological Inquiry, 11(3), 149159.https://doi.org/10.1207/S15327965PLI1103_03.

Vaculík, M., Vytásková, J., Procházka, J., \&Zalis, L. (2016). Mindfulness, job satisfaction and job performance: Mutual relationships and moderation effect. I. Simberova, F. Milichovsky, \& o. Zizlavsky (Eds.), Smart and efficient economy: Preparation for the future innovative economy, $148-156$.

Van Eerde, W. (2000). Procrastination: Self-regulation in initiating aversive goals. Applied Psychology, 49(3), 372-389. https://doi.org/10.1111/1464-0597.00021. 